\begin{tabular}{c|c|c|}
\hline & American Journal of Scientific Research and Essays \\
(ISSN:2475-7527)
\end{tabular}

\title{
Simulation analysis of impact grounding resistance of transmission lines
}

\section{Yunsheng $\mathrm{Xu}$ and Chunyan Li}

Department of mechanical engineering, North China Electric Power University, Baoding 071000, Hebei

\section{ABSTRACT}

In this paper, some methods of lightning protection measures are expounded in this paper, and then the influence of grounding resistance on ground resistance with current changing with current is revised by means of incomplete consideration of the influence factors of the impact grounding resistance in the standard.

Keywords: Transmission line; Grounding resistance; Lightning protection
*Correspondence to Author:

Yunsheng $\mathrm{Xu}$

Department of mechanical engineering, North China Electric Power University, Baoding 071000, Hebei

How to cite this article:

Yunsheng Xu,Chunyan Li. Simulation analysis of impact grounding resistance of transmission lines. American Journal of Scientific Research and Essays, 2018 3:9.

\section{eScîPub}

eSciPub LLC, Houston, TX USA.

Website: http://escipub.com/ 


\section{Overview of lightning protection}

Before the head of the pilot discharge channel from the thundercloud reaches the ground, the hitting point is uncertain, and the lightning is discharged to the object first. The strike distance is related to the amplitude of the lightning current. Wang Chunjie only reviewed the lightning protection grounding, and pointed out that lightning protection and grounding is a comprehensive problem, but there is no intention to improve $\mathrm{it}^{[1]}$. Liu Xiaogian concluded that the grounding resistance of the transmission line added to the lightning arrester and the tower can effectively protect the safety of the transmission line, but no optimization measures were put forward on the previous measures ${ }^{[2]}$. Through simulation calculation, it is concluded that the grounding resistance in the specification is unsafe and needs improvement.

There are two kinds of lightning overvoltages in overhead transmission lines, one is induced lightning overvoltage, the other is lightning overvoltage. When the descending pilot discharge from the thundercloud is close to the ground, the bound charge of the reverse polarity is induced on the near traverse, and the lightning strike is released into the free charge and flows to the two sides of the wire. The overvoltage is called the induced lightning overvoltage, the value is about $\mathrm{Ug}=25 \mathrm{lh} / \mathrm{s}(\mathrm{kV})$, and the $S$ is the distance of the lightning point to the wire $(\mathrm{m})$, generally above $65 \mathrm{~m}$. If we take $\mathrm{l}=100 \mathrm{kA}, \mathrm{h}=10 \mathrm{~m}, \mathrm{~S}=65 \mathrm{~m}, \quad$ and calculate $\mathrm{Ug}=385 \mathrm{kV}$, the positive impulse voltage of the 3 insulators is $350 \mathrm{kV}$, so it only poses a flashover threat to the $35 \mathrm{kV}$ and the following lines. Because of the high insulation level of 220kV transmission line, the harm of induced lightning overvoltage is generally small, and the key is direct lightning protection. The direct strike mine is divided into three different types of hit line equipment: 1) lightning strikes at the top of the tower, which is called the counterattack thunder; 2) lightning detours lightning through the lightning line directly on the wire, it is called the torpedo; 3) the center of the distance of the lightning arrester line.

\section{Counterattack}

Lightning current of lightning striking tower or nearby lightning conductor has great relation with tower height. This is mainly because when the tower height is high, the lightning current through the tower when hanging insulator string tower cross-bar formed tower induced voltage drop component becomes larger. Tower grounding resistance is also a factor affecting the lightning resistance level. When the tower grounding resistance is the same, the higher the tower height is, the lower the lightning resistance level will be.

Under various soil resistivity, the grounding resistance of the overhead transmission line tower can be refered to the recommended value of the grounding of the AC electrical device of $D L / T$ 621-1997 of China's electric power industry standard (see table 2-1).

Table 2-1 grounding resistance of overhead transmission lines and towers

\begin{tabular}{|c|c|c|c|c|c|}
\hline $\begin{array}{c}\text { Soil resistivity } \\
(\Omega . \mathrm{m})\end{array}$ & 010 & $\begin{array}{c}>100 \sim \\
500\end{array}$ & $\begin{array}{c}>500 \sim \\
1000\end{array}$ & $\begin{array}{c}>1000 \sim \\
2000\end{array}$ & $\begin{array}{c}> \\
2000\end{array}$ \\
\hline $\begin{array}{c}\text { Grounding } \\
\text { resistance }(\Omega)\end{array}$ & 10 & 15 & 20 & 25 & 30 \\
\hline
\end{tabular}

\section{Winding}

The protection function of the lightning conductor is to strike the lightning itself to protect the conductor from direct attack. But this protection is not one hundred percent effective. The proportion of shielding failure, that is, the ratio of the number of direct wires to the conductor and the total number of lightning strikes, is the shielding failure rate. The shielding failure rate is an important parameter to measure the lightning protection function.

The high voltage transmission line tower height, the large amplitude of the working voltage on the wire, is easier to lead up the lead on the wire, 
so the shielding performance of the high voltage line lightning arrester line is worse. This can be explained not only by the electrical geometry theory used to study the shielding performance of lightning arresters on transmission lines, but also by the operation conditions.

The main measure to improve the lightning performance of $\mathrm{HV}$ transmission lines is to use smaller lightning conductor to protect the conductor. The research shows that the working voltage on the conductor of the high voltage transmission line has great influence on shielding performance of the lightning conductor. This is mainly for the overwhelming majority of negative lightning strikes, although the working voltage polarity of the wire on the wire may be positive or negative and is possible, but the increment part of the former due to the strong attraction of lightning is more than the equal probability of negative polarity compared with the non-working voltage. The corresponding reduction of the shielding Flashover Rate under the operating voltage is much greater, which indicates that it is necessary and correct to consider the operating voltage in this study. The change trend of the impact grounding resistance is shown in Figure 3-1.

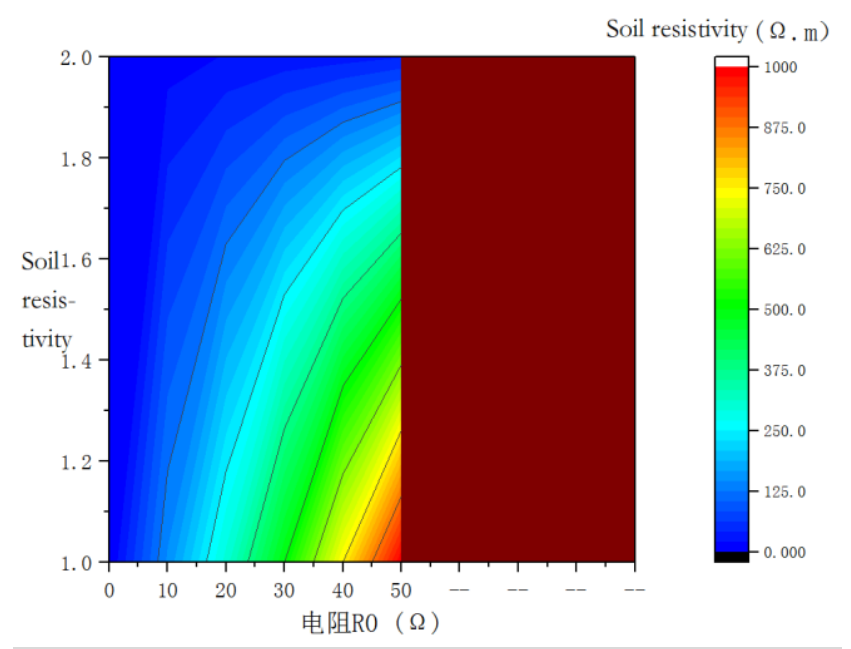

Figure 3-1. Soil resistivity changes with resistance

\section{Tripping in a lightning strike}

The calculation of return trip rate considers that the lightning strikes the tower directly or lightning strikes the lightning conductor near the tower, resulting in flashover of the insulator string or the gap between the tower. It is also possible that the gap between the conductor and the lightning conductor can be flashover in the middle of the lightning stroke. When lightning strikes the lightning conductor in the span, it will generate lightning overvoltage. The lightning overvoltage wave moves along the lightning protection line from the lightning strike point to the adjacent two sides. Due to the grounding effect of the tower, a negative reflection wave will return to the lightning strike point at the tower. When the reflected wave reaches the lightning strike point, if the lightning current has not reached the amplitude, the potential of the lightning strike point begins to decline when the negative reflection wave arrives. When the lightning point is located in the center of the span, the lightning overvoltage of the lightning point is the largest.

\section{The principle of the electrical geometric model method (EGM)}

The basic principle of EGM is that before the critical breakdown distance (short distance) of the guide head reaching the ground from the thundercloud to the ground, the hitting point is uncertain, which first reaches the distance of which object, that is to discharge to the object; the strike distance is close to the amplitude of the lightning current. The strike distance formula recommended by the IEEE standard is shown in formula (5-1) and (5-2).

$$
\begin{aligned}
& r_{\mathrm{s}}= 10 I^{0.65} \\
& r_{\mathrm{g}}= \begin{cases}{\left[3.6+1.7 \ln \left(43-y_{\mathrm{c}}\right)\right] I^{0.65} \quad\left(y_{\mathrm{c}}<40 \mathrm{~m}\right)} \\
5.5 I^{0.65} \quad\left(y_{\mathrm{c}} \geq 40 \mathrm{~m}\right)\end{cases} \\
& \mathrm{I} \quad-\text { Lightning current, } \mathrm{kA} ; \\
& \mathrm{rs}-\text { Lightning strike distance to ground line, m; } \\
& \text { rg - Lightning strike distance to the earth, m; } \\
& \text { yc - Average height of wire, m. }
\end{aligned}
$$

For the striking distance of conductor, the working voltage on it must be considered. The 
striking distance of lightning to the conductor can be determined by the following way.

\section{The principle of the electrical geometric model method (EGM)}

When the transmission line is struck by a foreign lightning, the external current after the lightning strikes will be transmitted through the grounding device to the earth and discharge in the earth. The huge current needs to be dispersed through the grounding resistance. Therefore, the emphasis is to simulate the way the current enters Earth grounding resistance, and the specification is to multiply a system using the power frequency grounding resistance. The number of impulse grounding resistance is obtained, but this method ignores the difference in resistivity between incoming soil current and soil. Therefore, this paper will consider the errors caused by the simulation method to reduce the errors, so as to reduce the cost for future design. The simulation results are shown as shown in Figure 6-1.

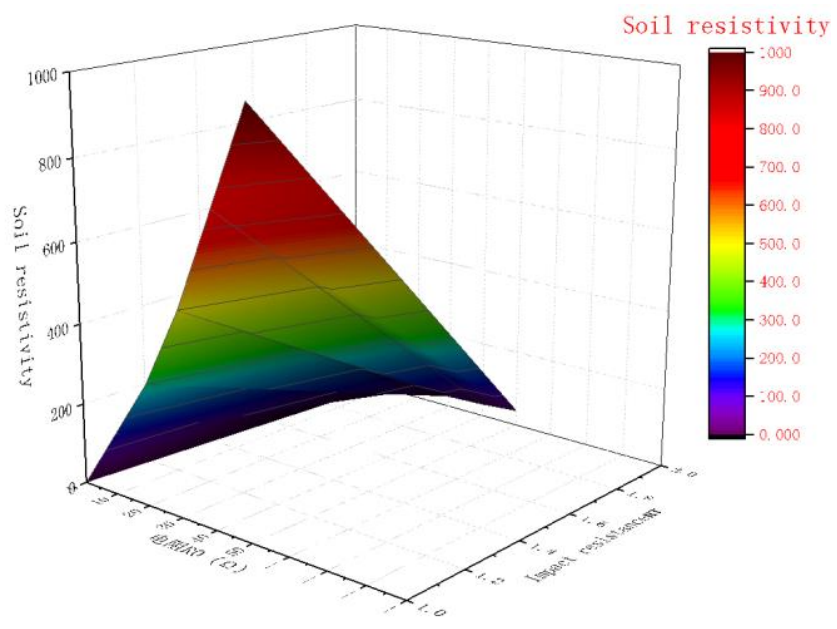

Figure 6-1. Ground impact resistance change

\section{Conclusion}

In this paper, the commonly used lightning protection measures are summarized. At the same time, the above measures are summed up, and the error of the calculation formula of the grounding impact resistance is analyzed.
The final results are obtained through simulation analysis, and the theoretical guidance for the protection measures of grounding resistance is further optimized.

\section{References}

[1] Wang C J, Zhu L Y, Sheng-Chang J I, et al. Present and Development of Lightning Protection for HV Transmission Lines and Substations[J]. Insulators \& Surge Arresters, 2010.

[2] Liu X Q, Dong X W, Yang R J. Simulation and Analysis on Lightning Protection Measures of Transmission Lines[J]. Insulators \& Surge Arresters, 2012. 